\title{
Delineation of Hydrocarbon Bearing Reservoirs from Surface Seismic and Well Log Data (Nembe Creek) In Niger Delta Oil Field.
}

\author{
${ }^{1}$ A.S. Ekine And ${ }^{2}$ A.A. Ibe \\ ${ }^{1,2}$ Department of Physics, University of Port Harcourt. Rivers State,Nigeria.
}

\begin{abstract}
Hydrocarbon reservoir has been delineated and their boundaries mapped using direct indicators from 3-D seismic and well log data from an oil field in Nembe creek, Niger Delta region. Well log signatures were employed to identify hydrocarbon bearing sands. Well to seismic correlation revealed that these reservoirs tied with direct hydrocarbon indicators on the seismic section. The results of the interpreted well logs revealed that the hydrocarbon interval in the area occurs between 6450ft to 6533ft for well A, 6449ft to 6537ft for well B and $6629 \mathrm{ft}$ to $6704 f \mathrm{ft}$ for well $C$; which were delineated using the resistivity, water saturation and gamma ray logs. Cross plot analysis was carried out to validate the sensitivity of the rock attributes to reservoir saturation condition. Analysis of the extracted seismic attribute slices revealed HD5000 as hydrocarbon bearing reservoir.
\end{abstract}

Keywords: Lamda-rho, Mu-rho, cross plot,P-Impedance.

\section{Introduction}

A quantitative and detailed description of reservoir architecture and its properties using well logs, seismic and geological information can strongly improve the economics of reservoir development and enhance its production. In the majority of reservoir development projects, the description of the reservoir is achieved through integrating well information and seismic data. The knowledge of reservoir dimension is an important factor in quantifying producible hydrocarbon reservoir (Schlumberger, 1989); and the needed information includes the thickness and area extent of the reservoir. These parameters are important because, they serve as veritable inputs for reservoir volumetric analysis (Edward, 1988). Precise determination of reservoir thickness is best obtained on well logs, especially using the gamma ray and resistivity logs (Asquith, 2004). All oil and gas produced are connected to accumulations in pore spaces of lithology like sand stone. The resistivity log can be used for evaluating the nature of intersticial fluid. Since these logs are recorded against depth, the hydrocarbon bearing interval can be determined. Accurate mapping of the lateral dimension of the reservoir can be obtained from well logs, where the data are abundantly available or direct hydrocarbon indicators (Brown, 1984).

Hydrocarbons are formed in geologic traps which are combinations of rock structures that will keep oil and gas from migrating either vertically or laterally (Win Qin, 1995). Majority of the traps in the Niger Delta are structural; to locate them, horizons are picked and faults mapped at seismic in lines and cross lines.

The aim of this paper is to delineate a hydrocarbon bearing reservoirs, using an integrated technique.

\section{Petroleum Occurrence}

The Niger Delta basin is situated at the southern end of Nigeria boarding the Atlantic Ocean and extends from about longitude $3^{0} \mathrm{E}$ to $9^{0} \mathrm{E}$ and latitude $4^{0} 3^{\mathrm{I}} \mathrm{N}$ to $5^{0} 2^{\mathrm{I}} \mathrm{N}$. Petroleum occurs throughout the Agbada formation of the Niger Delta. However, several directional trends form an oil rich belt having the largest field and lowest gas to oil ratio (Doust and Omatsola, 1990). The belt extends from the northwest offshore area to the southeast onshore along a number of north-south trends in the area of Port Harcourt. The position of the oil rich belt to oil prone marine source rocks deposited adjacent to the delta lobes, suggests that the accumulation of these source rocks was controlled by pre-tertiary structural sub-basins, related to basement structures (Haack,1997). The hydrocarbon habitat model was constructed for central portion of the delta, including some of the oil rich belt and these relates to the deposition of Akata formation to the sand or shale units in the Agbada formation (Stacher, 1995). The Agbada formation is the central portion of the delta that fits a shallow ramp model, with mainly high stand (hydrocarbon bearing sands) and transgressive (sealing shale) system; it provides pathways for petroleum migration and formed structural traps that accumulate hydrocarbon. 


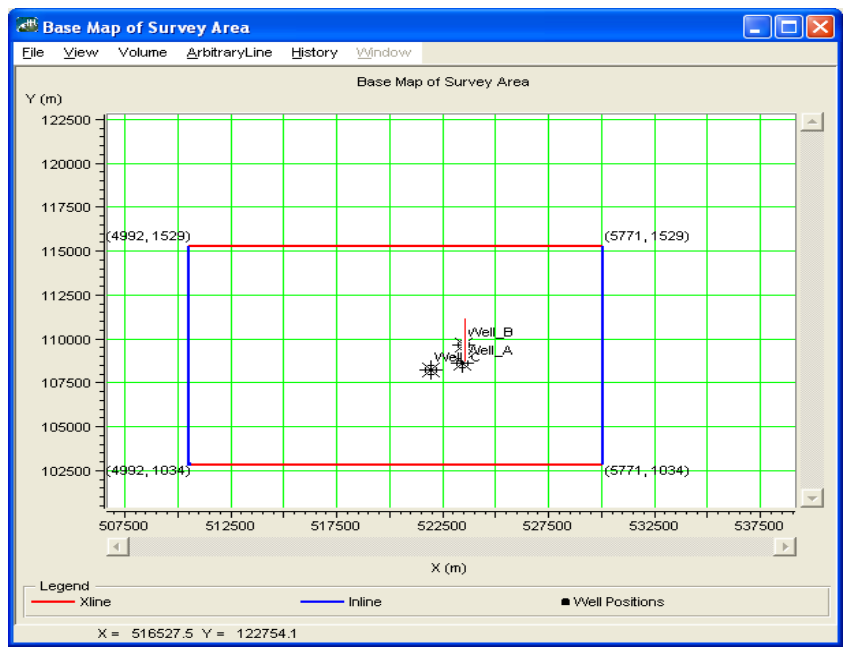

Fig. 1: Base map of the study area

\section{Methodology}

Integrating seismic and well log data into Hampson-Russell programs were adopted to evaluate the sand bodies of the area under investigation. These digitized data was in LAS format; and the relevant wire line $\log$ signatures were employed to identify hydrocarbon bearing reservoir. The well logs used for the interpretation include gamma ray, resistivity, water saturation and density logs; which exhibit dominantly shale/sand/shale sequence, which is a typical Niger Delta formation. These wells were analyzed in terms of fluid type and lithology; regions of low gamma ray, high resistivity and low water saturation are mapped as sand lithology, which are also known as regions of high hydrocarbon saturation(See figure 2). Well logs were edited to limit the number of bad data points they contain, in a bid to ensure the reliability of the results from their integration in seismic interpretation. The logs were de-spiked using a median filter, with the operator length of $2 \mathrm{n}+1$; where $\mathrm{n}$ is the number of spikes. These were applied on P-wave velocity and density logs to limit the abundance of data spikes. Before applying seismic inversion, an accurate depth to time conversion were performed in order to match the scale of the well log acoustic impedance data to that of vertical scale of the seismic data so as to allow spatial correlation. This conversion is carried out using the sonic log; and the process simultaneously create a composite trace from the $\log$ (see figure 3 ).

Cross plot analysis was carried out to determine the reservoir and also to ascertain those attributes that are sensitive to 3-D effects caused by changes in the reservoir fluid saturation and pressure. These cross plot analysis provides efficient way of interpreting seismic inversion and predict reservoir properties where there is no well control (Nabajyoti, 2005). The common form of the plot is between P-impedance and Lamda-rho, Pimpedance and Mu-rho etc. However cross plots are visual representations of the relationship between two variables, which are used to detect significant departures from a back ground trends (see figure 4).

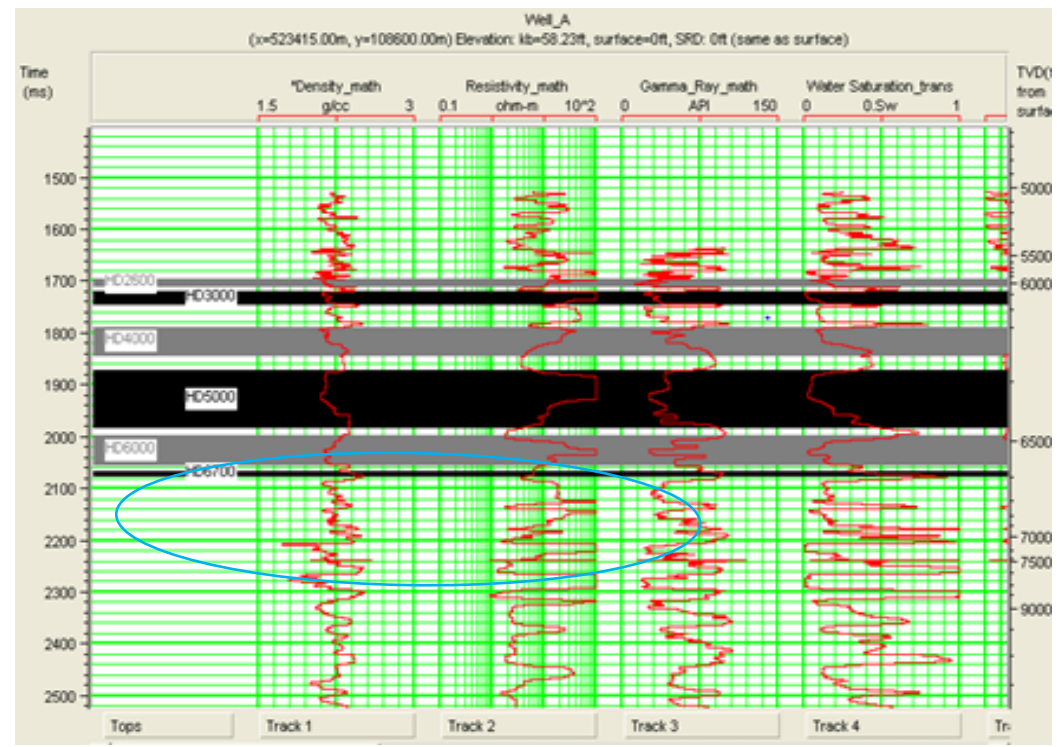

Fig.2: Suite of Well log signatures 


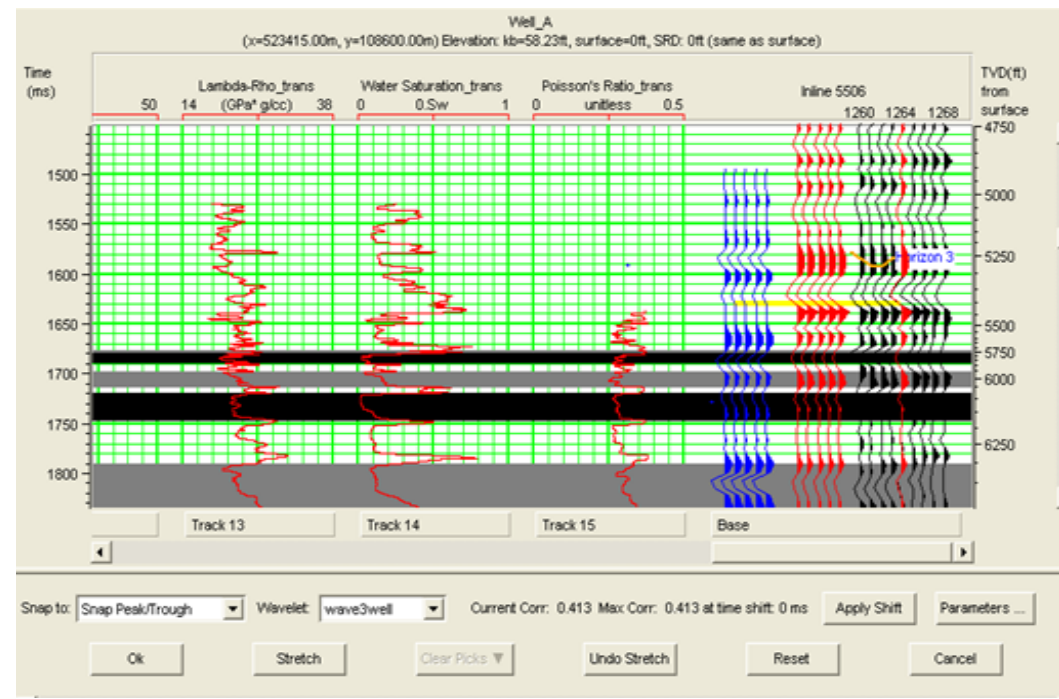

Fig.3: well to seismic correlation.

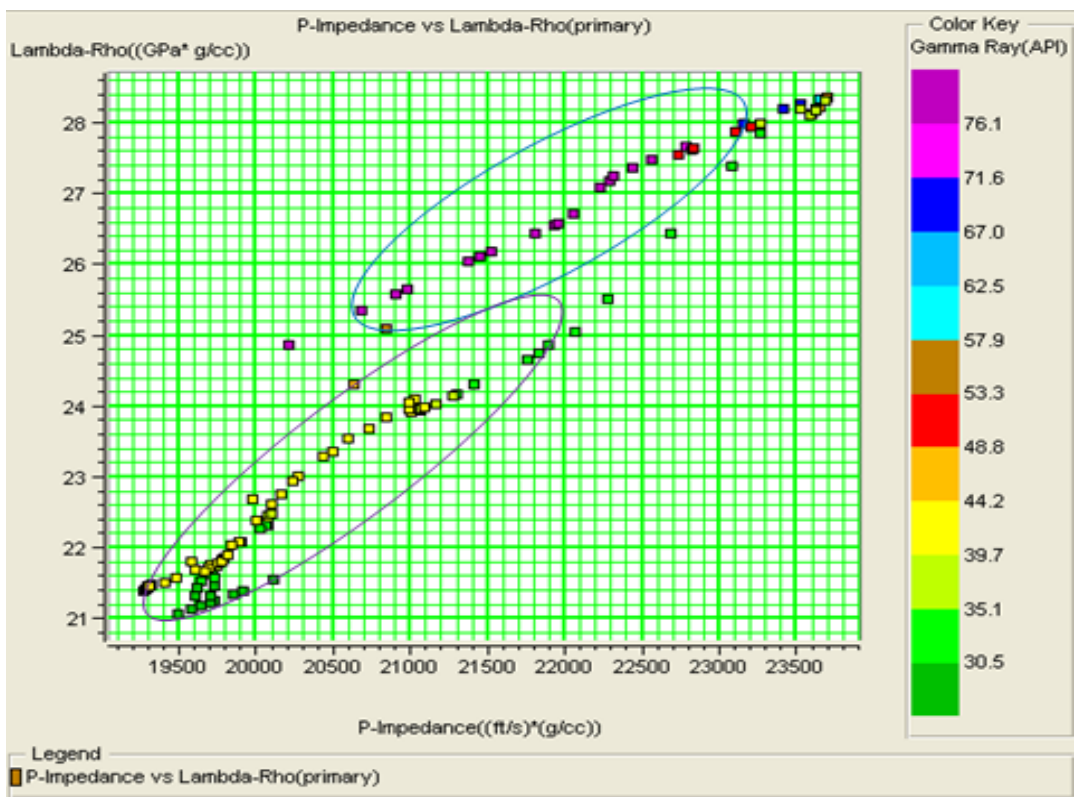

Fig.4: Rock attribute cross plot

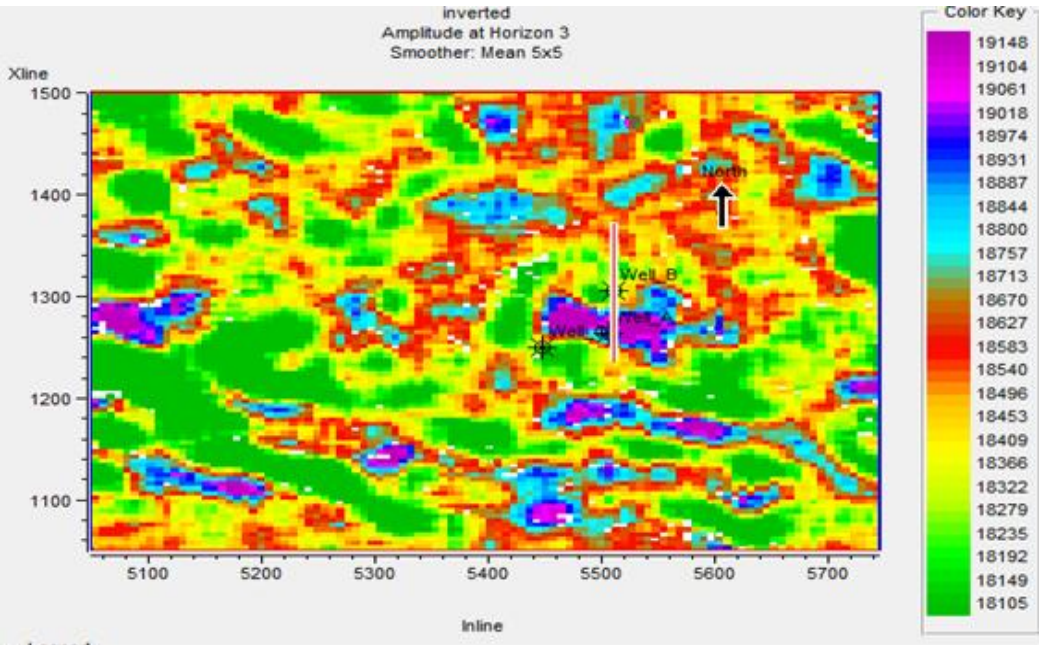

Fig.5: P-impedance rock attribute template 


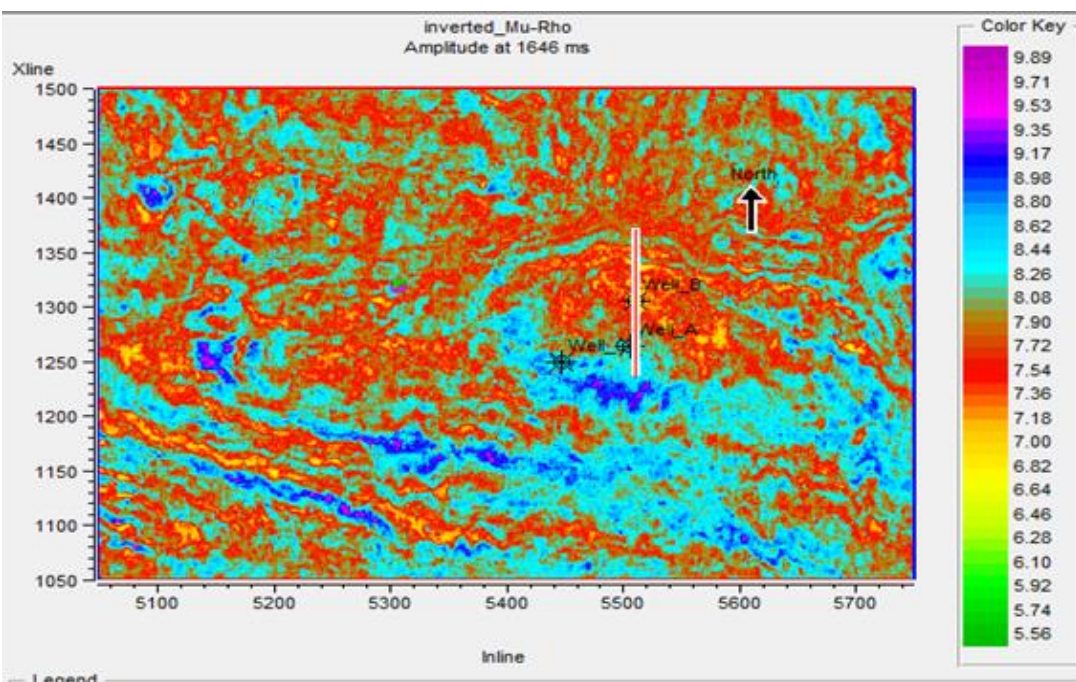

Fig.6: Mu-rho rock attribute template.

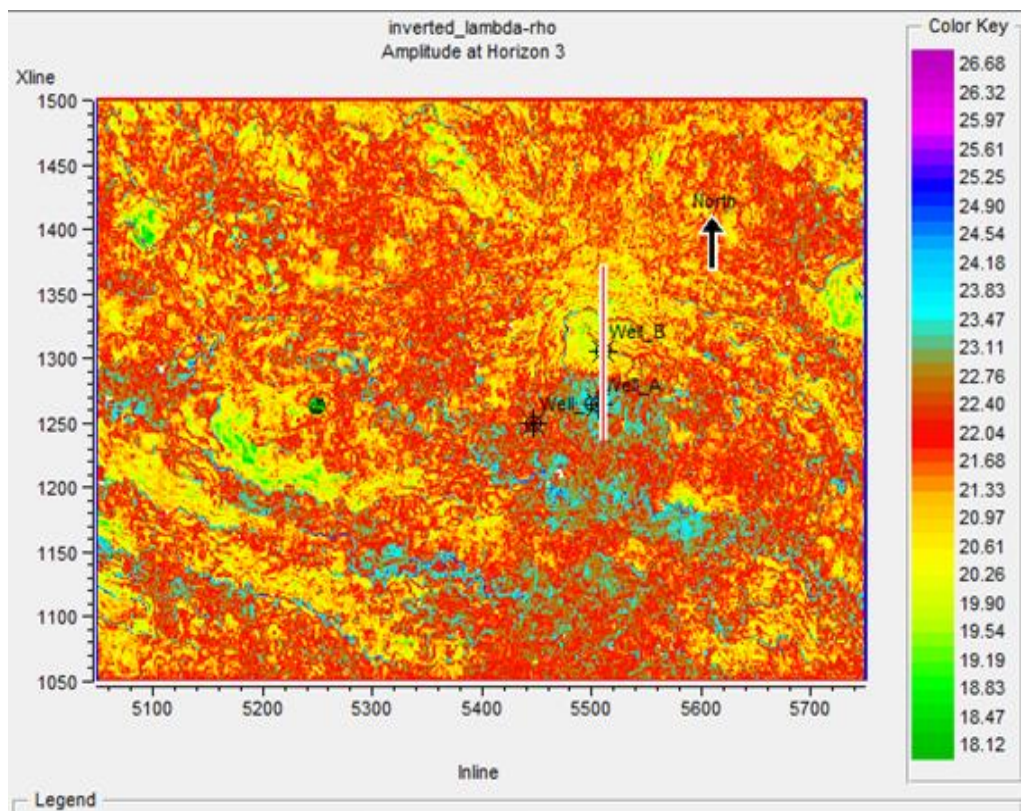

Fig.7: Lamda-rho rock attribute template.

\section{Results}

The rock attribute templates were extracted from the acoustic impedance volume. Changes in the rock attributes were evaluated for probable hydrocarbon prospects. The P-impedance, Lamda-rho and Mu-rho attributes were found to be most robust in lithology and fluid discrimination within the reservoir from the cross plot analysis. 3-D inversion was performed to directly generate acoustic impedance volumes from which the rock attributes were extracted. Relatively low P-impedance, Lamda-rho and high Mu-rho were observed around the producing well locations and other by-passed areas in the rock attribute template taken; which are characterized as reservoir sand bodies that is attributed to hydrocarbon charged zones (see figure 5-7). Finally, it was fluid saturation that is responsible for the decrease and increase in rock attribute value.

\section{Conclusion}

This research involves the delineation of hydrocarbon bearing reservoir using well logs and seismic data. From the well log analysis, HD5000 was identified as producible hydrocarbon reservoir using rock physics templates and well to seismic tie revealed that hydrocarbon bearing reservoirs was associated with bright and dim spots. 


\section{Acknowledgement}

We thank Shell Petroleum Development Company Port Harcourt division for providing the data set and the provision of Geophysical work station in the Department of Physics, University of Port Harcourt. Our thanks also go to Hampson-Russell Limited for providing the software and its licence.

\section{Reference}

[1]. Brown, A.R; Wright, R.M. (1984): Mapping of possible gas sand in the North Sea, Geophysics Journal Vol. 49; 680p-714p.

[2]. Doust and Omatsola (1990): Passive margin basins, Tulsa; American Association of Petroleum Geologists memoir 48: 239p-248p.

[3]. Edward, J.D; Falti, J.L; Vail, P.S and Levitt, P.R (1988): Basin well logs analysis. AAPG methods in exploration 45p.

[4]. Haack, R.G; Sundaraman, P and Daal (1997): Niger Delta Petroleum system, in extended Abstracts, AAPG/ABGP Hedberg research symposium Petroleum systems of South Atlantic margin, November 16-19. Rio de Janeiro Brazil.

[5]. Nabajyoti, B (2005): Rock Physics template, analysis of well logs for lithology and fluid classification 8th Biennial International conference and exposition on Petroleum Geophysics.

[6]. Schlumberger (1989): Log interpretation principles and application; Schlumberger wire line and testing Houston, Texas 21p-89p.

[7]. Stacher, P (1995): Present understanding of the Niger Delta hydrocarbon, Geology of Deltas Rotterdam; 257p-260p.

[8]. Win Qin (1995): Reservoir delineation using 3D seismic data of the pring Hu field East China, Unpublished M.Sc thesis, Univer sity of Colorado Boulder $6 \mathrm{p}-8 \mathrm{p}$ 